\title{
PENINGKATAN KOMPETENSI PEDAGOGIK GURU DALAM MENYUSUN RENCANA PELAKSANAAN PEMBELAJARAN BERBASIS KURIKULUM 2013 MELALUI SUPERMIK PINTER DI SMP BINAAN KABUPATEN SRAGEN
}

\author{
Warjito \\ Pengawas Sekolah SMP Kabupaten Sragen \\ warjito_was@yahoo.com
}

\begin{abstract}
This study aims to improve the pedagogic competence of teachers in preparing the implementation plan of learning (RPP) based on Curriculum 2013 through "SUPERMIK PINTER". This study is a school action research with subjects of teachers in 5 targeted junior high schools that implementing the 2013 Curriculum starting from the 2017/2018 school year: SMP Negeri 1 Gemolong, SMP Negeri 1 Sidoharjo, SMP Negeri 1 Sukodono, SMP Negeri 2 Sukodono and SMP Negeri 1 Gesi amounted to 25 people. This study consists of two cycles; each cycle consists of four stages: planning, action, acting, observing, and reflection. The research time for 3 months is August to October 2017. The results showed that, with the SUPERMIK PINTER, pedagogic competence of teachers in preparing the RPP-based Curriculum 2013 has increased from the initial conditions to cycle I and cycle II. The improvement is shown by the teacher's quality data as follows: initial conditions: enough: 25 people (100\%), good: none (0\%) and very good: none (100\%); cycle I: enough: none (0\%), good: 19 people (76\%) and very good: 6 people (24\%); while cycle II: enough: none (0\%), good: none (0\%) and very good: 25 people (100\%). Based on the theoretical study and the results of the action, the conclusion is SUPERMIK PINTER can improve teacher pedagogic competence in RPP on Curriculum2013 in 5 SMPs of Sragen District in the Lesson Year 2017/2018.
\end{abstract}

Keywords: pedagogic competence, academic supervision, RPP based on Curriculum 2013

Abstrak. Penelitian ini bertujuan untuk meningkatkan kompetensi pedagogik guru
dalam menyusun rencana pelaksanaan pembelajaran (RPP) berbasis Kurikulum
2013 melalui "SUPERMIK PINTER" yaitu supervisi akademik dengan pendampingan
individual terprogram. Penelitian ini merupakan penelitian tindakan sekolah dengan
subyek guru-guru di 5 SMP binaan yang mengimplementasikan Kurikulum 2013
mulai tahun pelajaran 2017/2018 yaitu SMP Negeri 1 Gemolong, SMP Negeri 1
Sidoharjo, SMP Negeri 1 Sukodono, SMP Negeri 2 Sukodono dan SMP Negeri 1
Gesi berjumlah 25 orang. Penelitian ini terdiri dari dua siklus, setiap siklus terdiri dari
empat tahap yaitu perencanaan, pelaksanaan tindakan, pengamatan, dan refleksi. Waktu
penelitian selama 3 bulan yaitu Agutus sampai dengan Oktober 2017 . Hasil penelitian
menunjukkan bahwa dengan SUPERMIK PINTER tersebut kompetensi pedagogik
guru dalam menyusun RPP berbasis Kurikulum 2013 mengalami peningkatan dari
kondisi awal ke siklus I dan siklus II. Peningkatan tersebut ditunjukkan data kualitas
RPP guru sebagai berikut: kondisi awal: cukup: 25 orang (100\%), baik: tidak ada
(0\%) dan amat baik: tidak ada (100\%); siklus I: cukup: tidak ada (0\%), baik: 19 
orang (76\%) dan amat baik: 6 orang (24\%); sedangkan siklus II: cukup: tidak ada $(0 \%)$, baik: tidak ada (0\%) dan amat baik: 25 orang (100\%). Berdasarkan kajian teori dan hasil tindakan, simpulan hasil penelitian bahwa "SUPERMIK PINTER"dapat meningkatkan kompetensi pedagogik guru dalam menyusun RPP Berbasis Kurikulum 2013 di 5 SMP binaanKabupaten Sragen Tahun Pelajaran 2017/2018.

Kata kunci: kompetensi pedagogik, supervisi akademik, RPP berbasis Kurikulum 2013

\section{Pendahuluan}

Kondisi nyata yang terjadi di sekolah binaan, berdasarkan hasil supervisi akademik yang peneliti lakukan selaku pengawas sekolah, masih ditemukan beberapa guru yang mengalami kesulitan terkait dengan penyusunan RPP berbasis Kurikulum 2013. Pertama; guru belum memahami benar selukbeluk penyusunan RPP berbasis Kurikulum 2013, maka secara otomatis rasa malas akan muncul ketika hendak menyusunnya. Kedua; perubahan Kurikulum 2013 akan berimbas kepada perubahan susunan komponen dan kaidah-kaidah dalam menyusun RPP. Perubahan ini seringkali menyulitkan guru. Ketiga; minimnya penguasaan teknologi komputerisasi para guru pasti dalam menysun RPP berbasis Kurikulum 2013 akan memakan waktu yang cukup lama, dan pasti juga akan menjadi permasalahan yang menyulitkan guru. Sebagai jalan pintasnya mayoritas guru dalam menyusun RPP berbasis Kurikulum 2013 copi paste utuh dari RPP orang lain atau dari hasil MGMP tanpa adanya suatu pengembangan dan penyesuaian.

Rencana Pelaksanaan Pembelajaran (RPP) merupakan suatu rencana yang menggambarkan prosedur dan manajemen pembelajaran untuk mencapai satu atau lebih kompetensi dasar yang ditetapkan dalam standar isi dan jabarkan dalam silabus (Mulyasa, 2007:212). Menurut Ginting (dalam Fadlillah, M., 2014:144) Rencana Pelaksanaan Pembelajaran merupakan skenario pembelajaran yang menjadi pegangan bagi guru untuk menyiapkan, menyelenggarakan, dan mengevaluasi hasil kegiatan belajar dan pembelajaran. Selanjutnya Permendikbud Nomor 22 Tahun
2016 tentang Standar Proses Pendidikan Dasar dan Menengah menjelaskan bahwa Rencana Pelaksanaan Pembelajaran Rencana Pelaksanaan Pembelajaran (RPP) adalah rencana kegiatan pembelajaran tatap muka untuk satu pertemuan atau lebih. RPP dikembangkan dari silabus untuk mengarahkan kegiatan pembelajaran peserta didik dalam upaya mencapai Kompetensi Dasar (KD). Jadi Rencana Pelaksanaan Pembelajaran (RPP) adalah suatu bentuk perencanaan pembelajaran yang akan dilaksanakan oleh pendidik dalam kegiatan pembelajaran untuk mencapai tujuan yang telah ditetapkan dalam kurikulum sesuai dengan kebutuhan siswa, sekolah, dan daerah.

Menurut Permendikbud Nomor

22 Tahun 2016 tentang Standar Proses Pendidikan Dasar dan Menengah, komponen RPP berbasis Kurikulum 2013 terdiri dari 1) identitas sekolah yaitu nama satuan pendidikan; 2) identitas mata pelajaran atau tema/subtema; 3) kelas/semester; 4) materi pokok; 5) alokasi waktu ditentukan sesuai dengan keperluan untuk pencapaian KD dan beban belajar dengan mempertimbangkan jumlah jam pelajaran yang tersedia dalam silabus dan KD yang harus dicapai; 6) tujuan pembelajaran yang dirumuskan berdasarkan $\mathrm{KD}$, dengan menggunakan kata kerja operasional yang dapat diamati dan diukur, yang mencakup sikap, pengetahuan, dan keterampilan; 7) kompetensi dasar dan indikator pencapaian kompetensi; 8) materi pembelajaran, memuat fakta, konsep, prinsip, dan prosedur yang relevan, dan ditulis dalam bentuk butir-butir sesuai dengan rumusan indikator ketercapaian kompetensi; 9) metode pembelajaran, digunakan oleh pendidik untuk 
mewujudkan suasana belajar dan proses pembelajaran agar peserta didik mencapai KD yang disesuaikan dengan karakteristik peserta didik dan KD yang akan dicapai; 10) media pembelajaran, berupa alat bantu proses pembelajaran untuk menyampaikan materi pelajaran; 11) sumber belajar, dapat berupa buku, media cetak dan elektronik, alam sekitar, atau sumber belajar lain yang relevan; 12) langkah-langkah pembelajaran dilakukan melalui tahapan pendahuluan, inti, dan penutup; dan 13) penilaian hasil pembelajaran.

Sedangkan prinsip-prinsip penyusunan RPP berbasis Kurikulum 2013 menurut Permendikbud Nomor 22 Tahun 2016 tentang Standar Proses Pendidikan Dasar dan Menengah adalah sebagai berikut: 1) Perbedaan individual peserta didik; 2) Partisipasi aktif peserta didik; 3) Berpusat pada peserta didik; 4) Pengembangan budaya membaca dan menulis; 5) Pemberian umpan balik dan tindak lanjut RPP; 6) Penekanan pada keterkaitan dan keterpaduan antara KD, materi pembelajaran kegiatan pembelajaran, indikator pencapaian kompetensi, penilaian, dan sumber belajar dalam satu keutuhan pengalaman belajar; 7) Mengakomodasi pembelajaran tematik-terpadu, keterpaduan lintas mata pelajaran, lintas aspek belajar, dan keragaman budaya; 8) Penerapan teknologi informasi dan komunikasi secara terintegrasi, sistematis, dan efektif sesuai dengan situasi dan kondisi.

Mengingat sangat urgennya kompetensi pedagogik guru dalam menyusun RPP berbasis Kurikulum 2013, maka pengawas sekolah harus melakukan pembinaan guru secara berkesinambungan dan terus-menerus (continuous profesional development). Hal ini sesuai dengan amanat Permendiknas No.12 Tahun 2007 tentang Standar Pengawas Sekolah/Madrasah bahwa seorang pengawas sekolah harus memiliki 6 standar kompetensi yang salah satunya adalah kompetensi supervisi akademik. Konsekuensi kompetensi ini, menuntut seorang pengawas sekolah harus memberikan bantuan profesional kepada guru dalam mencarikan solusi terhadap permasalahan yang mereka dihadapi.

Dalam membantu guru menyusun RPP berbasis Kurikulum 2013, dalam penelitian ini peneliti selaku pengawas sekolah mencoba mengembangkan strategi SUPERMIK PINTER yaitu supervisi akademik dengan pendampingan individual terprogram. Yang dimaksud supervisi akademik yaitu serangkaian kegiatan membantu guru mengembangkan kemampuan mengelola proses pembelajaran untuk mencapai tujuan pembelajaran (Daresh, 1989, Glickman, et al, 2007)dengan tujuan membantu guru mengembangkan potensinya, mengembangkan kurikulum, mengembangkan kelompok kerja guru, dan membimbing penelitian tindakan kelas (PTK) (Glickman, et.al. 2007, Sergowati, 1987). Prinsip-prinsip yang perlu diperhatikan dan direalisasikan dalam supervisi akademik adalah: 1) praktis, 2) sistematis, 3) obyektif, 4) realistis, 5) antisipatif, 6) konstruktif, 7) kooperatif, 8) kekeluargaan, 9) demokratis, 10) aktif, 11) humanis, 12) berksinambungan, dan 13) terpadu.

Prosedur supervise akademik merupakan rangkaian kegiatan supervisi untuk memberikan bantuan dan bimbingan kepada kepala sekolah dan guru agar termotivasi melakukan perbaikan-perbaikan yang diperlukan dalam bidang akademik dengan cara memilih pendekatan, metoda, dan teknik supervisi yang tepat sesuai tujuan yang ingin dicapai. Prosedur supervisi akademik terdiri atas 4 tahap, yaitu: 1) Tahap Persiapan, meliputi menyiapkan instrument dan jadwal bersama, 2) Tahap Pelaksanaan, yaitu pelaksanaan observasi supervisi baik secara langsung maupun tidak langsung, 3) Tahap pelaporan, meliputi: a) mengidentifikasi hasil pengamatan pada saat observasi, b) menganalisis hasil supervisi, c) mengevaluasi bersama antara supervisor dengan kepala sekolah dan guru, d) membuat catatan hasil supervisi yang didokumentasikan 
sebagai laporan, dan 4) Tahap tindak lanjut, meliputi: a) mendiskusikan dan membuat solusi bersama, b) memberitahukan hasil pelaksanaan supervisi akademik, dan c) mengkomunikasikan hasil pelaksanaan supervisi akademik kepada kepala sekolah dan guru.

Teknik supervisi akademik terdiri atas dua macam, yaitu teknik supervisi individual dan teknik supervisi kelompok. Teknik supervisi individu ada 5 macam yaitu: 1) kunjungan kelas, 2) observasi kelas, 3) pertemuan individual, 4) kunjungan antar kelas, dan 5) menilai diri sendiri.Teknik supervisi kelompok ada 13 macam, yaitu: 1) kepanitiaan, 2) kerja kelompok, 3) laboratorium dan kurikulum, 4) membaca terpimpin, 5) demonstrasi pembelajaran, 6) darmawisata, 7) kuliah/studi, 8) diskusi panel, 9) perpustakaan, 10) organisasi profesional, 11) bulletin supervise, 12) pertemuan guru, 13) lokakarya atau konferensi kelompok.

Dari beragam teknik ini berkaitan dengan permasalahan dalam penelitian ini, peneliti memfokuskan pada teknik supervisi akademik individu dengan bentuk kegiatan pendampingan individual yang dilaksanakan secara terprogram atau direncanakan baik materi maupun jadwal waktunya. Teknik pendampingan ini diterapkan karena menurut Eric Parsloe (dalam Modul Usaid Prioritas: Praktik yang Baik dalam Fasilitasi dan Pendampingan) teknik pendampingan merupakan alat pemberdayaan dan pengembangan personal yang ampuh, merupakan cara yang efektif dalam menolong seseorang mengembangkan karirnya, merupakan hubungan kerja yang bermanfaat didasarkan pada sikap saling percaya dan menghormati sehingga akan terwujud tiga hal yaitu: motivating, inspiring dan challenging. Dengan pertimbangan inilah maka strategi SUPERMIK PINTER diharapkan akan mampu meningkatkan kompetensi pedagogik guru dalam menyusun RPP berbasis Kurikulum 2013.

\section{Metode Penelitian}

Setting penelitian ini dilaksanakan di 5 SMP binaan yang mulai Tahun Pelajaran 2017/2018 mengimplementasikan Kurikulum 2013, yaitu SMP Negeri 1 Gemolong, SMP Negeri 1 Sidoharjo, SMP Negeri 1 Sukodono, SMP Negeri 2 Sukodono dan SMP Negeri 1 Gesi.Waktu penelitian ini dilakukan selama 3 bulan yaitu Agustus sampai Oktober 2017 pada semester gasal Tahun Pelajaran 2017/2018.Penelitian dilakukan dalam 2 siklus.Setiap siklus terdiri dari empat tahap yaitu perencanaan (planning), pelaksanaan tindakan (acting), pengamatan (observing), dan refleksi (reflection) dan masing-masing siklus dilakukan $2 \mathrm{kali}$ pertemuan atau kegiatan.

Subyek tindakan dalam penelitian ini adalah guru-guru di 5 SMP binaan yang berdasarkan hasil supervisi akademik pengawas sekolah nilai RPP nya dikategorikaan cukup.Dari 5 SMP binaan tersebut semuanya ada 25 guru.

Penelitian ini dalam pengumpulan data menggunakan metode observasi, wawancara, studi dokumen dan angket berupainstrumen telaah Rencana Pelaksanaan Pembelajaran (RPP) Kurikulum 2013.Instrumen ini terdiri dari 25 item yang mencakup 9 komponen RPP, yaitu: 1) Identitas mata pelajaran; 2) Perumusan indikator; 3) Perumusan tujuan pembelajaran; 4) Pemilihan materi ajar; 5) Pemilihan sumber belajar; 6) Pemilihan media belajar; 7) Model pembelajaran; 8) Skenario pembelajaran; dan 9) Penilaian. Setiap item terdiri dari tiga pilihan jawaban yaitu 1, 2, dan 3.Skor jawaban dinilai 1 (jika jawaban tidak ada/tidak sesuai), 2 (jika jawaban kurang lengkap/sesuai sebagain), dan 3 (jika jawaban sudah lengkap/sesuai seluruhnya). Kategori kualitas RPP dinyatakan amat baik (AB) jika nilainya $90<\mathrm{AB} \leq 100$; baik (B) jika nilainya $80<\mathrm{B} \leq 90$; cukup (C) jika nilainya $70<\mathrm{C} \leq 80$; dan kurang $(\mathrm{K})$ jika nilainya $\leq 70$.

Penelitian ini merupakan Penelitian Tindakan Sekolah (PTS) atau School 
Action Research (SAR) dengan menerapkan "SUPERMIK PINTER yaitusupervisi akademik dengan pendampingan individual terprogram.untuk meningkatkan kompetensi pedagogik guru dalam menyusun RPP berbasis Kurikulum 2013.

\section{Hasil Penelitian dan Pembahasan}

\section{A. Deskripsi data Kondisi Awal}

Dalam penelitian ini, untuk memperoleh data awal, peneliti selaku pengawas sekolah melakukan kegiatan pra tindakan yaitu melakukan supervisi akademik berupa menilai RPP yang dibuat guru di 5 SMP binaan yang hasilnya digunakan sebagai acuan dalam melakukan tindakan berikutnya. Hasil dari kegiatan ini kemudian dipilih nilai RPP yang kategorinya cukup atau kurang ada sejumlah 25 orang guru. Selanjutnya data nilai RPP 25 guru ini dijadikan data awal penelitian yaitu 25 orang kategorinya $\mathrm{C}$.

\section{Siklus I}

Tindakan peneliti dengan strategi SUPERMIK PINTERdilakukan melalui kegiatan supervisi akademik dengan pendampingan individual terprogram. Kegiatan pendampingan kepada guru secara individual dilakukan terprogram yaitu dua kali pertemuan dengan fokus materi pendampingan penyusunan RPP berbasis Kurikulum 2013.Dari hasil SUPERMIK PINTER selama dua kali pertemuan, kemudian dilakukan penilaian I terhadap
RPP berbasis Kurikulum 2013 yang disusun guru,hasilnya adalah sebagai berikut: RPP dengan kategori cukup: tidak ada ( $0 \%)$, baik: 19 orang (76\%), dan amat baik: 6 orang (24\%).

\section{SiklusII}

Tindakan peneliti selaku pengawas sekolah masih melanjutkan SUPERMIK PINTER berupa kegiatan supervisi akademik dengan pendampingan individual terprogram lanjutan. Kegiatan pendampingan kepada guru secara individual masih sama yaitu dilakukan terprogram selama dua kali pertemuan dengan fokus materi pendampingan penyusunan RPP berbasis Kurikulum 2013. Dari hasil SUPERMIK PINTER selama dua kali pertemuan, kemudian dilakukan penilaian II terhadap RPP berbasis Kurikulum 2013 yang disusun guru, hasilnya adalah sebagai berikut: RPP dengan kategori cukup: tidak ada ( $0 \%)$, baik: tidak ada $(0 \%)$, dan amat baik: 25 orang $(100 \%)$.

\section{B. Hasil Tindakan}

Setelah dilakukan tindakan pada siklus I dan siklus II berupa SUPERMIK PINTER, RPP berbasis Kurikulum 2013 yang disusun guru hasilnya menunjukkan peningkatan dari data awal ke siklus I dan ke siklus II. Adapun data peningkatan nilai RPP berbasis Kurikulum 2013 tersebut selengkapnya dirangkum pada table 1 berikut.

Tabel 1. Rangkuman data peningkatan nilai RPP berbasis Kurikulum 2013

\begin{tabular}{|c|c|c|c|c|c|c|c|}
\hline \multirow{2}{*}{ No } & \multirow{2}{*}{ Kategori RPP } & \multicolumn{2}{|c|}{ Kondisi Awal } & \multicolumn{2}{c|}{ Siklus I } & \multicolumn{2}{c|}{ Siklus II } \\
\cline { 3 - 8 } & & Jumlah & $\%$ & Jumlah & $\%$ & Jumlah & $\%$ \\
\hline 1 & Cukup & 25 & 100 & 0 & 0 & 0 & 0 \\
\hline 2 & Baik & 0 & 0 & 19 & 76 & 0 & 0 \\
\hline 3 & Amat Baik & 0 & 0 & 6 & 24 & 25 & 100 \\
\hline
\end{tabular}

\section{Pembahasan}

Penelitian tindakan sekolah ini berangkat dari kondisi riil kompetensi pedagogik guru dalam menyusun RPP berbasis Kurikulum
2013 di 5 SMP binaan peneliti. Dari hasil supervisi akademik yang dilakukan diindikasikan ada 25 orang guru yang kualifikasi RPP nya tergolong kategori cukup. 
Data ini menjadi data awal pra tindakan yang akan ditingkatkan melalui pemberian tindakan SUPERMIK PINTER yaitu supervisi akademik dengan pendampingan indidual terprogram. Setelah tindakan diimplementasikan pada siklus I dengan dua kali pertemuan untuk masing-masing guru, maka hasil refleksinya menunjukkan ada peningkatan namun belum maksimal yaitu ada 19 orang guru RPP-nya berkategori baik dan baru 6 orang guru yang RPP-nya berkategori amat baik. Untuk itu masih merekomendasikan agar tindakan berupa SUPERMIK PINTER tetap dilanjutkan.

Pada siklus II peneliti masih melakukan tindakan lanjutan berupa SUPERMIK PINTER yaitu melakukan supervisi akademik dengan pendampingan individual terprogram selama dua kali pertemuan untuk masing- masing guru.Hasil refleksinya menunjukkan ada peningkatan signifikan dibandingkan dari data awal dan siklus I yaitu semua guru berjumlah 25 orang sudah mampu menyusun RPP berbasis Kurikulum 2013 dengan kategori amat baik. Dengan hasil ini maka rekomendasinya adalah pemberian tindakan diakhiridan tidak dilanjutkan lagi.

Dengan membandingkan antara data awal pra tindakan dengan data hasil tindakan siklus I dan siklus II, maka telah terjadi peningkatan kompetensi pedagogik guru dalam menyusun RPP berbasis Kurikulum 2013 melalui penerapan SUPERMIK PINTER. Untuk memperjelas di bawah ini disajikan grafik data peningkatan kompetensi guru dalam menyusun RPP berbasis Kurikulum 2013 mulai dari kondisi awal, siklus I dan siklus II:

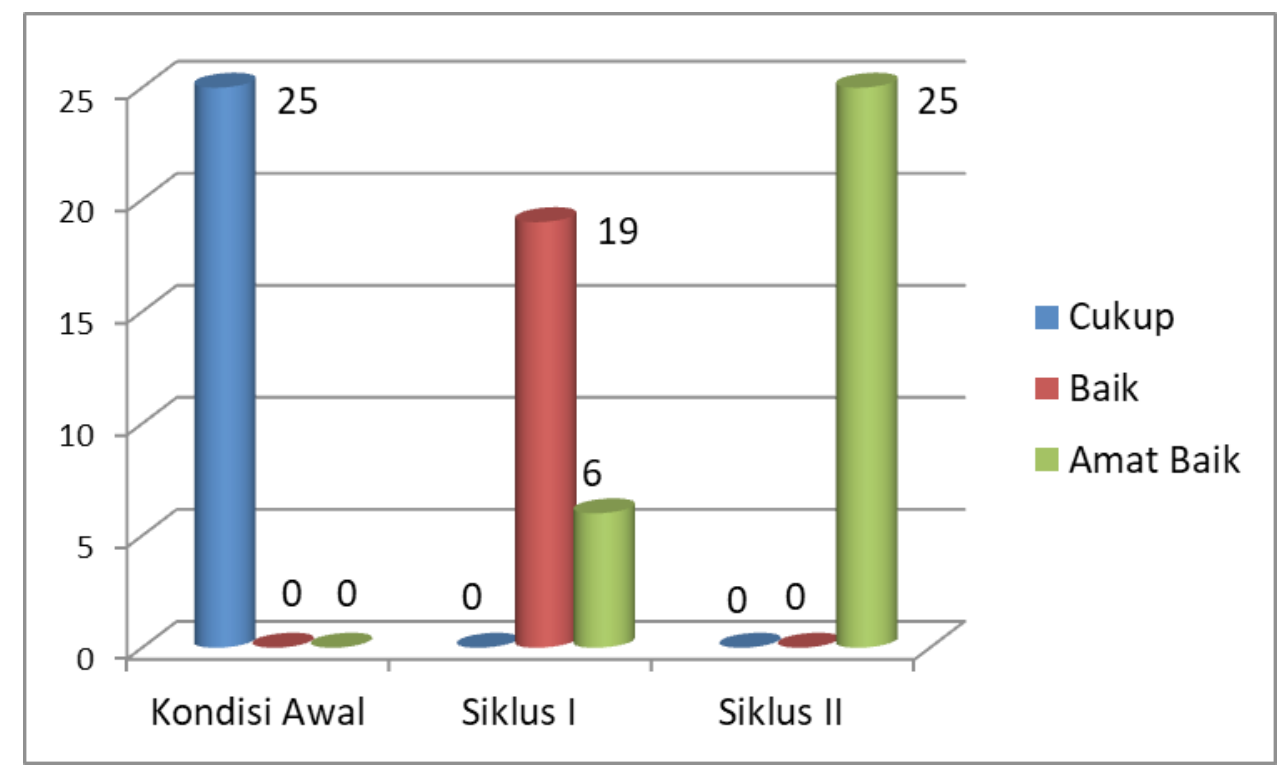

Grafik 1. Peningkatan kompetensi guru dalam menyusun RPP berbasis Kurikulum 2013 mulai dari kondisi awal, siklus I dan siklus II

Dari grafik di atas diketahui bahwa SUPERMIK PINTERefektif meningkatkan kompetensi pedagogik guru dalam menyusun RPP berbasis Kurikulum 2013. Ada beberapa alasan mengapa teknik pendampingan individual ini dipilih dan diterapkan dalam penelitian ini. Dalam modul pelatihan Praktik yang Baik dalam Fasilitasi dan Pendampingan (Usaid Prioritas, 2013) dijelaskan karena teknik pendampingan: 1)
Mampu meningkatkan kinerja guru dengan semangat saling belajar dan membelajarkan antara pendamping dan guru yang didampingi, 2)Mampu meningkatkan kinerja guru empat kali lebih cepat dibandingkan dengan hanya memberikan pelatihan, 3) Mampu memberikan solusi dengan lebih focus terhadap keterbatasan yang dimiliki, dan 4) Mampu membentuk pribadi yang reflektif.

Efektivitas SUPERMIK PINTER, 
dikarenakan strategi ini dalamimplementasinya memiliki keunggulan-keunggulan, antara lain: 1) berorientasi untuk membantu dan membimbing guru mengembangkan kemampuannya, memfasilitasi, berbagi sumber, memecahkan masalah, umpan balik dan refleksi yang terpisah dari evaluasi; 2) dilakukan secara humanis dalam jalinan hubungan kemanusiaan yang harmonis, terbuka, jujur, sabar, antusias diselingi dengan humor agar tidak terjadi suasana tegang; 3) ditumbuhkembangkan kreativitas dan inovasi guru dalam mengembangkan kemampuannya; 4) dilaksanakan secara demokratis artinya supervisor tidak mendominasi tetapi lebih membangun suasana asah, asih, asuh; 5) dalam mengembangkan kemampuan guru didesain secara ofisial, sehingga jelas waktu mulai dan berakhirnya program pengembangan tersebut.

Namun teknik pendampingan individual ini di samping memiliki banyak keunggulan, secara empiric ternyata ditemukan juga beberapa kekurangan, diantaranya: 1) membutuhkan waktu yang lebih panjang diibandingkan dengan teknik pelatihan atau sejenisnya, 2) Pendamping benar-benar dituntut memiliki komitmen yang tinggi dan konsistensi, kesabaran serta ketulusan hati yang tidak mudah dimiliki oleh sembarang orang, 3) Pendamping dituntut memiliki kecakapan interpersonal yang tinggi dan kemampuan komunikasi yang efektif.

Dengan hasil kajian teoritis dan empiris yang telah terbukti tersebut,maka SUPERMIK
PINTER dapat direkomendasikan sebagai salah satu strategi alternatif bagi pengawas sekolah dan kepala sekolah dalam melaksanakan tugas pokok fungsinya melaksanakan supervise akademik.

\section{Simpulan}

Berdasarkan kajian teori dan hasil penelitian dapat diambil kesimpulan bahwa peningkatan kompetensi pedagogik guru dalam menyusun RPP berbasis Kurikulum 2013 dapat dilakukan melalui"'SUPERMIK PINTER" yaitu supervisi akademik dengan pendampingan individual terprogram.

\section{Saran}

Berdasarkan kesimpulanpenelitianini, peneliti menyampaikan saran sebagai berikut:(1) Pengawas sekolahdalam meningkatkan kompetensi pedagogik guru dalam menyusun RPP berbasis Kurikulum 2013 dapat menerapkan strategi SUPERMIK PINTER yaitu supervisi akademik dengan pendampingan individual terprogram; (2) Kepala sekolah dalam melaksanakan supervisi akademik kepada guru agar hasilnya maksimal juga dapat menerapkan strategi SUPERMIK PINTER; (3) Guru dalam meningkatkan kompetensi pedagogik, khususnya dalam menyusun RPP berbasis Kurikulum 2013 hendaknya banyak belajar dan berlatih dengan memanfaatkan forum MGMP baik di tingkat sekolah maupun tingkat kabupaten.

\section{Daftar Pustaka}

Daresh, J.C. 1989. Supervision as a Proactive Process. White Plains. NY: Longman.

Departemen Pendidikan Nasional.Penelitian Tindakan Sekolah. Direktorat Jenderal Peningkatan Mutu Pendidik dan Tenaga Kependidikan. Jakarta.

Departemen Pendidikan Nasional. 2009. Petunjuk Teknis Pembuatan Laporan Penelitian Tindakan Sekolah Sebagai Karya Tulis Ilmiah Dalam Kegiatan Pengembangan Profesi Pengawas Sekolah. Jakarta.

Fadhillah, M. 2013. Implementasi Kurikulum 2013. Dalam Pembelajaran SD/MI, SMP/MTs \& $S M A / M A$.Yogyakarta.Ar-Ruzz Media.

Kementerian Pendidikan dan Kebudayaan.2017. Panduan Kerja Pengawas Sekolah Pendidikan Dasar dan Menengah. Jakarta: Direktorat Jenderal Guru dan Tenaga Kependidikan. 
Direktorat Pembinaan Tenaga Kependidikan. Dikdasmen.

Kementerian Pendidikan dan Kebudayaan. 2014. Supervisi Akademik Implementasi Kurikulum 2013. Bahan Ajar Implementasi Kurikulum 2013 untuk Pengawas Sekolah. Jakarta: Pusat Pengembangan Tenaga Kependidikan.

Kementerian Pendidikan dan Kebudayaan. 2016. Supervisi Akademik. Program Pengawas Sekolah Pembelajar Tahun 2016. Direktorat Jenderal Guru dan Tenaga Kependidikan. Direktorat Pembinaan Tenaga Kependidikan. Dikdasmen.

Madyo Eko Susilo. 2012. Karya Tulis Ilmiah (KTI) Bidang Kepengawasan.Direktorat Pembinaan Pendidik dan Tenaga Kependidikan. Direktorat Jenderal Pendidikan Menegah. Jakarta.

Mahfud. 2013. Langkah Mudah Melakukan Penelitian Tindakan Sekolah (PTS/PTKP).

Mulyasa, E. 2007.Kurikulum Tingkat Satuan Pendidikan. Bandung. Remaja Rosdakarya.

Peraturan Menteri Pendidikan Nasional Nomor 12 Tahun 2007 tentang Standar Pengawas Sekolah/Madrasah.

Peraturan Menteri Pendidikan Nasional Nomor 16 Tahun 2007 tentang Standar Kualifikasi Akademik dan Kompetensi Guru.Jakarta.

Peraturan Menteri Pendidikan dan Kebudayaan Nomor 22 Tahun 2016 tentang Standar Proses Pendidikan Dasar dan Menengah.Jakarta.

Peraturan Pemerintah Nomor 19 Tahun 2005 tentang Standar Nasional Pendidikan.

Sudjana, Nana. 2009. Standar Kompetensi Pengawas Dimensi dan Indikator.Jakarta : Binamitra Publishing.

Suharsimi Arikunto, Suhardjono, Supardi. 2006. Penelitian Tindakan Kelas. Jakarta. PT Bumi Aksara.

Supardi, Suhardjono. 2013. Strategi Menyusun Penelitian Tindakan Kelas. Berdasarkan Permenpan dan Reformasi Birokrasi No. 16 Tahun 2009.Yogyakarta.Penerbit Andi Offset.

Undang-Undang Republik Indonesia Nomor 20 Tahun 2003 tentang Sistem Pendidikan Nasional.

Undang-Undang Guru Republik Indonesia Nomor 14 Tahun 2005 tentang Guru dan Dosen.

Usaid Prioritas. 2013. Praktik yang Baik dalam Fasilitasi dan Pendampingan. Modul Pelatihan. Jakarta. 